\title{
Direct Determination of Total Arsenic and Arsenic Species by Ion Chromatography Coupled with Inductively Coupled Plasma Mass Spectrometry
}

\author{
Sang-Ho Nam, Jae-Jin Kim, and Soung-Sim Han \\ Deparment of Chemistr. Mokpo National Chiversit, 61 Dorm-Ri, Chunghve-1/von, Muan-Gum. Chonnam $534-729$, Korea \\ Received April 16, 2003
}

\begin{abstract}
The simultaneous determination of As(III). As(V). and DMA has been performed by ion chromatography (IC) coupled with inductively coupled plasma-mass spectrometry (ICP-MS). The separation of the three arsenic species was achieved by an anionic separator column (AS 7) with an isocratic elution sy'stem. The separated species were directly detected by' ICP-MS as an element-selective detection method. The IC-ICP-MS technique was applied for the determination of arsenic species in a NIST SRM I643d water sample. An As(III) only was detected in the sample. The detection limits of As(III). As(V) and DMA were 0.31. 0.45, and $2.09 \mathrm{ng} / \mathrm{mL}$. respectively. It was also applied for the determination of arsenic species in a human urine obtained by a volunteer. and three arsenic species were identified. The determination of total As in human urines that were obtained from 25 volunteers at the different age was also carried out by ICP-MS.
\end{abstract}

Key Words : Arsenic species. Ion chromatography. ICP-MS

\section{Introduction}

The chemical speciation of an element in a sample is to quantitatively determine the different chemical forms of an element. The forms can be differentiated by the different oxidation states, inorganic and organic elements. The chemical speciation of an element has been considered as an important topic in various scientific areas because its biological and nutritional effects rely on its chemical forms existed in the sample. ${ }^{1-6}$ As has been known to be toxic. but its toxicity depends on its chemical forms. ${ }^{7-22}$ As(III) is the most toxic inorganic species conmonly found in environmental and biological samples. As(V) is also toxic, but is relatively less toxic than As(III). Its different forms are the methylated arsenic species which are methylarsonic acid (MMA) and dimetlyylarsinic acid (DMA). ${ }^{l(1}$ The methylated arsenic species have been known to be much less toxic than the inorganic species. Accordingly. for a risk assessment of As. its different arsenic forms should be identified and determined in various samples. Many investigators have reported the arsenic speciation using various techniques. ${ }^{7-22}$ The best teclunique of all analytical methods to effectively separate and detect the different arsenic species seems to be a coupling technique which combine the chromatographic method with the spectroscopic method. Several studies have been done for arsenic chenical speciation in biological fluid such as urine $e^{35}$ and food like rice ${ }^{5}$ using liquid and ion chromatography coupled with mass spectrometry. The chromatography has been utilized to separate the different chemical species. but its conventional detectors could not detect selectively the element. Thus, it suffered from the interference of other existing ions and compounds. Consequentially, the element-selective methods for chromatographic methods have been seriously required. Above all other methods, Ar ICP-MS has been most favored due to its excellent detection capability of most elements. Ar ICP-MS has clearly advanced elemental analy sis with various advantages over other analytical methods. The main advantages are the excellent detection capabilities. wide linear dynamic range of most elements, multielements detection capability, and isotope ratio analy sis. ${ }^{23-25}$

This paper describes the determination of total and speciated arsenic in urines obtained from volunteers at various age using IC coupled with Ar ICP-MS. In particular, the isocratic eluent system for ion chromatography was used to separate $\mathrm{As}(\mathrm{III})$. $\mathrm{As}(\mathrm{V})$ and DMA in urine. Various concentrations of nitric acid as an eluent were investigated for the effective separation of As(III). As(V) and DMA in a sample. Detection limits and linear dynamic ranges of As(III). As(V) and DMA were also studied with IC coupled with Ar ICP-MS. The arsenic species and total arsenic in a NIST SRM 1643d water sample and a NIST SRM 2670 urine sample. respectively. were investigated for the accuracy of the analytical method. The analysis of urines obtained from 25 volunteer for total arsenic was perfonmed with $\mathrm{Ar}$ ICP-MS.

\section{Experimental Section}

Instrumentation. The chromatographic system used in this work is a Dionex (Dionex Corporation. Sunnyvale, CA, 94088-3603. USA) model GP 40 ion chromatograply pump. Samples were introduced into the analytical column by direct injection with a sample loop. The sample injection volume was $100 \mu \mathrm{L}$. An analytical column AS 7 (Dionex) together with a guard columı $\mathrm{AG} 7$ was used. The effluent from the analytical column was introduced directly into ICP-MS (Thermo Elemental. 27 Forge Parkway Franklin. MA 02038. USA) model VG PQ Excell. The general schematic diagram for this study is shown in Figure 1. Details of the instnumental and operating condition are described in Table 1. 


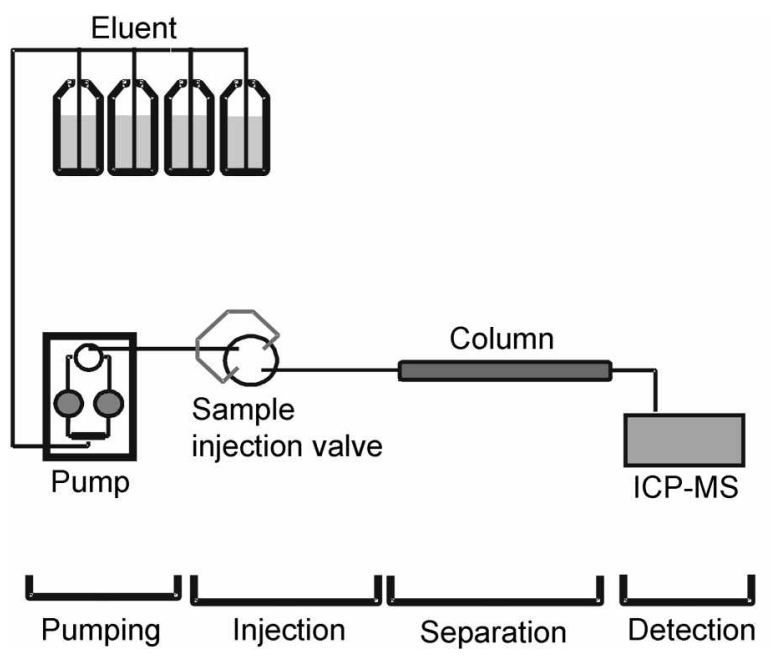

Figure 1. Schematic diagram of ICP-MS with IC.

Reagents. Analytical stock solution for DMA (Dimethylarsinic acid) was obtained from Aldrich. (Aldrich Chemical Company Inc., 1001 West Saint Paul Avenue, Milwaukee. Wisconsin 53233. U.S.A). As(III) and As(V) were prepared from sodium metaarsenite and sodium hexafluoroarsenate (Aldrich). respectively. The eluent of $10 \mathrm{mM} \mathrm{HNO}_{3}$ was prepared from concentric nitric acid (VHG Labs, Inc., 180 Zachary Rd., Manchester, NH 03109. U.S.A). The pHs of eluent and sample were controlled by $\mathrm{HNO}_{3}$ (VHG Labs) and $\mathrm{NH}_{4} \mathrm{OH}$ (Aldrich). All solutions were also prepared with $18 \mathrm{MW} \cdot \mathrm{cm}$ distilled deionized water obtained from the PURELAB Plus water purification system (ELGA. High street, Lane End High Wycombe Buckinghamshire HP 143 JH. U.K).

The urines were first filtered through a $0.25 \mu \mathrm{m}$ nylon filter (Whatman Inc., 9 Bridewell Place. Clifton. New Jersey 07014 . USA), then the $2 \mathrm{~mL}$ of filtered urine was diluted with $8 \mathrm{~mL}$ of deionizde water before being injected to IC. ICP-MS.

Table 1. Instrumental and operating conditions

\begin{tabular}{ll}
\hline Sampling and skinmer cone & Nickel \\
Spray chamber & $\begin{array}{l}\text { lmpact bead spray chamber } \\
\left(3^{\circ} \mathrm{C} \text { water cooling }\right)\end{array}$ \\
RF power & $1350 \mathrm{~W}$ \\
Retlect power & $1.2 \mathrm{~W}$ \\
Sample uptake rate & $1.0 \mathrm{mLL} / \mathrm{min}$ \\
Argon gas flow rate & \\
Coolant gas & $13 \mathrm{~L} / \mathrm{min}$ \\
Auxiliary gas & $0.32 \mathrm{~L} / \mathrm{min}$ \\
Nebulizer gas & $0.90 \mathrm{~L} / \mathrm{min}$ \\
Acquisition parameter & \\
Data acquisition mode & Profile TRA \\
Dwell time & $100 \mathrm{~ms}$ \\
Number of replicates & 1 \\
Duration time & $300 \mathrm{~s}$ \\
Monitoring mass & $-\mathrm{As}$ \\
\hline
\end{tabular}

\section{Results and Discussion}

various concentrations of $\mathrm{HNO}_{3}$ as an eluent for the effective separation of arsenic species were investigated. First of all, the eluent of $0.5 \mathrm{mM} \mathrm{HNO}_{3}$ was used to separate the arsenic species with an anionic separator column (AS 7). As the results are shown in Figure 2. the separation of As(V) from DMA was not completed. Thus, the concentration of the eluent was increased by $1.0 \mathrm{mM}$. at last the separation of three arsenic species was completed as the cluromatogram is shown in Figure 3. In this study, the used concentration of $\mathrm{HNO}_{3}$ as an eluent for the separation of arsenic species by AS 7 column was $10 \mathrm{mM} \mathrm{HNO}$. The three cluromatographic peaks of $\mathrm{ng} / \mathrm{mL}$ As(III). As(V) and DMA could be clearly seen with IC-ICP-MS. The calibration curves were obtained for As(III). As(V) and DMA. The results are shown in Figure 4 . The lowest points for each species correspond to the minimum detection limits of the arsenic species with IC.ICP-MS. The analytical calibration curve shows the linear dynamic ranges of As(III), As(V). and DMA are at least 3-4 orders of magnitude. The correlation coefficients ranged from 1.000 to 0.999 .

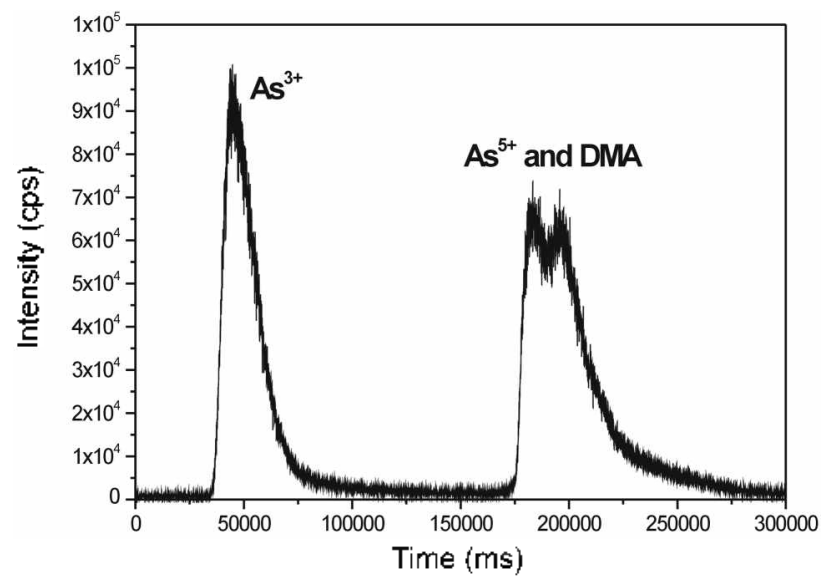

Figure 2. Chromatogram of $50 \mathrm{ng} / \mathrm{mL} \mathrm{As}^{3+}, \mathrm{As}^{5+}$ and DMA: eluent $0.5 \mathrm{mM} \mathrm{HNO}_{3}$, sample $\mathrm{pH} 8$.

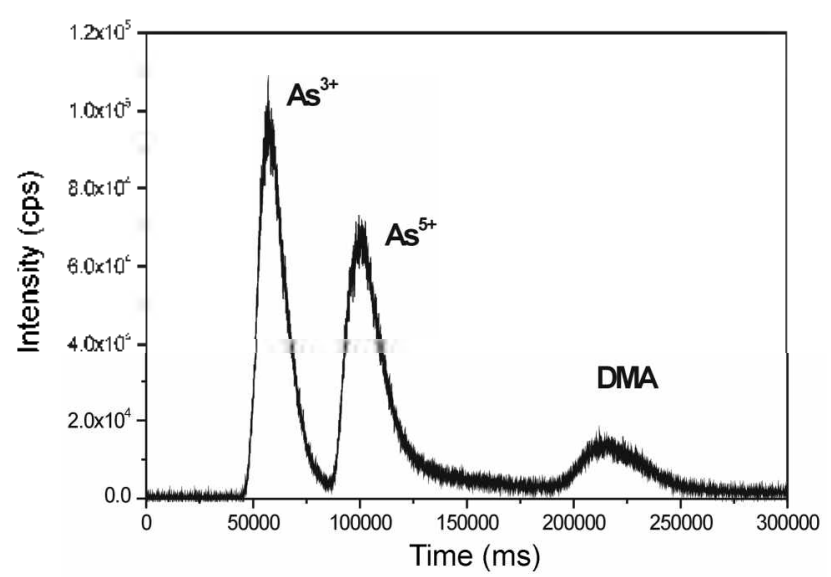

Figure 3. Chromatogram of $50 \mathrm{ng} / \mathrm{mL} \mathrm{As}^{3+}, \mathrm{As}^{5+}$ and DMA: eluent $10 \mathrm{mM} \mathrm{HNO}_{3}$, sample $\mathrm{pH} 8$. 


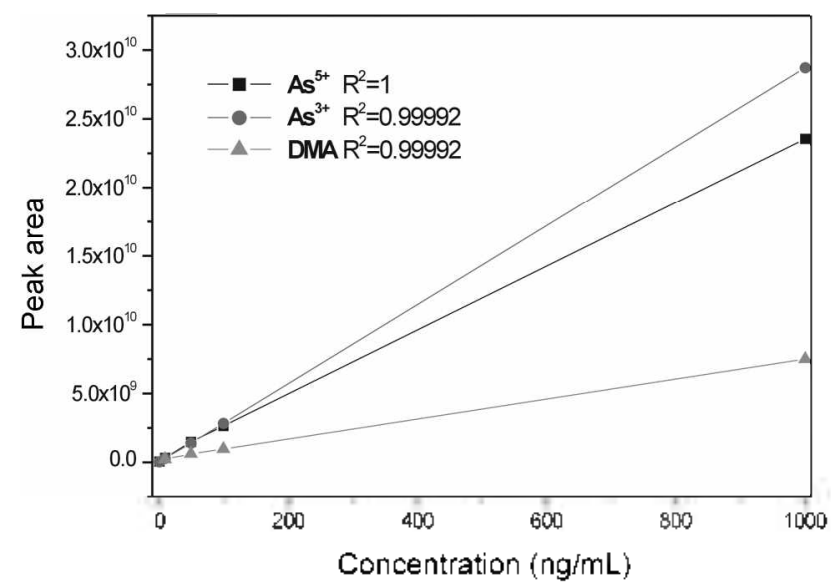

Figure 4. Calibration curves of $\mathrm{As}(\mathrm{III}), \mathrm{As}(\mathrm{V})$ and DMA.

Table 2. Detection limits of As(III), As( V) and DMA

\begin{tabular}{ccc}
\hline Method & Species & $\begin{array}{c}\text { Detection limit } \\
(\mathrm{ng} / \mathrm{mL})\end{array}$ \\
\hline ICP-MS & $\mathrm{As}$ & 0.036 \\
IC-ICP-MS & $\mathrm{As}^{3+}$ & 0.31 \\
& $\mathrm{As} s^{5+}$ & 0.45 \\
& $\mathrm{DMA}$ & 2.09 \\
\hline
\end{tabular}

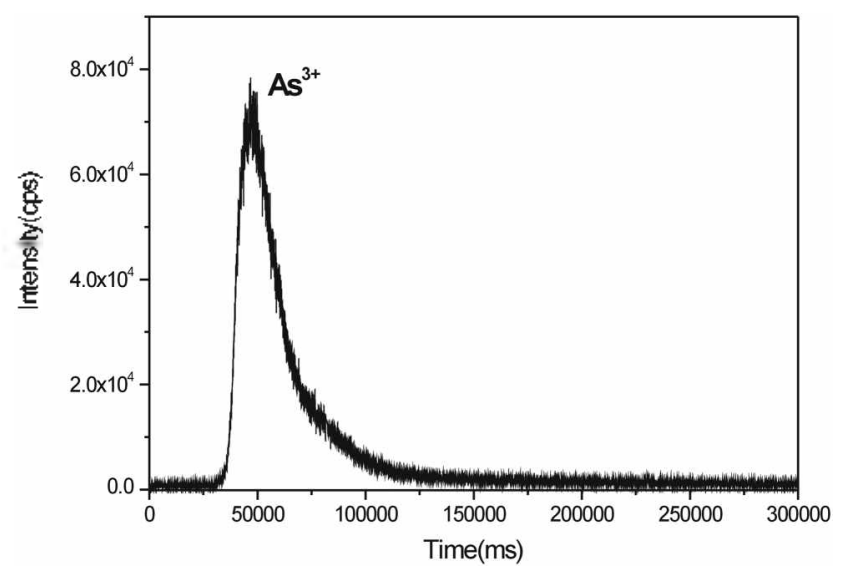

Figure 5. Detemination of As in a NIST SRM 2670.

Detection limits of As(III), As(V) and DMA are shown in Table 2. The detection limit of As with ICP-MS is $0.036 \mathrm{ng} /$ $\mathrm{mL}$. but the detection limits of $\mathrm{As}(\mathrm{III})$ and $\mathrm{As}(\mathrm{V})$ are 0.31 and $0.45 \mathrm{ng} / \mathrm{mL}$, respectively. The deterioration of detection limit by a factor of 10 may be mainly due to the dilution effect of eluent in the colunn when the ion chromatography are coupled with ICP-MS for the separation of arsenic species. The detection limit of DMA is $2.0 \mathrm{ng} / \mathrm{mLL}$ which is worse than those of inorganic arsenic species approximately by a factor of 5 . The worse detection limit of DMA may be due to the lower atomization and ionization efficiency of DMA than those of inorganic species in ICP.

The accuracy of the developed method was investigated for a NIST SRM 1643d water sample by comparing the measured total of all As species with the certified total As
Table 3. Detemuation of As m a NIST SRM 2670

\begin{tabular}{ccc}
\hline Element & $\begin{array}{c}\text { Measured value } \\
(\mathrm{mg} / \mathrm{L})\end{array}$ & $\begin{array}{c}\text { Certified value } \\
(\mathrm{mg} / \mathrm{L})\end{array}$ \\
\hline As & $0.60 \pm 0.007$ & $0.48 \pm 0.10$ \\
\hline
\end{tabular}

concentration. As the results are shown in Figure 5. the As(III) only existed in the water sample. The sample was analyzed by using a standard calibration curve of As(III). The measured concentration of As (III) was $53.51 \mathrm{ng} / \mathrm{mL}$. It agreed well with the certified value. The method was also tested for a NIST SRM 2670 urine sample by comparing the measured total As with the certified total As concentration. As the results are shown in Table 3 , the total measured concentration was $0.60 \pm 0.007 \mathrm{ng} / \mathrm{mL}$ that was within the $95 \%$ confidence limit of certified value of $0.48 \pm 0.10 \mathrm{ng} / \mathrm{mL}$. The results indicated the mass spectral interference of $\mathrm{ArCl}^{-}$did make a positive effect on the determination of As.

We are interesting in the total As concentration in urines obtained from people at different age because the As can be accumulated in the body. Unines were obtained by 25 volunteers at various age who were living in south-western area of South Korea. Five urines samples were obtained from the children at the age of 1 to 10 . The urines were first filtered through a $0.25 \mu \mathrm{m}$ nylon, then the $2 \mathrm{~mL}$ of filtered urine was diluted with $8 \mathrm{~mL}$ of deionized water before being injected to IC-ICP-MS. The total arsenic was determined in five urines with IC.P-MS. The average concentration of arsenic was $69.3 \pm 0.46 \mathrm{ng} / \mathrm{mL}$. Another

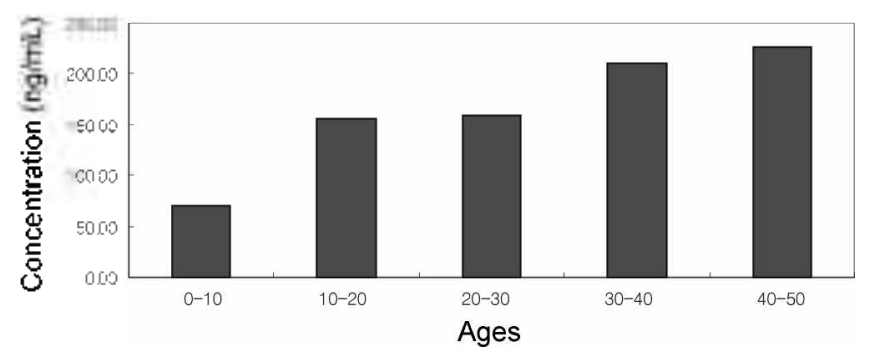

Figure 6. Detemnination of total arsenic in unnes.

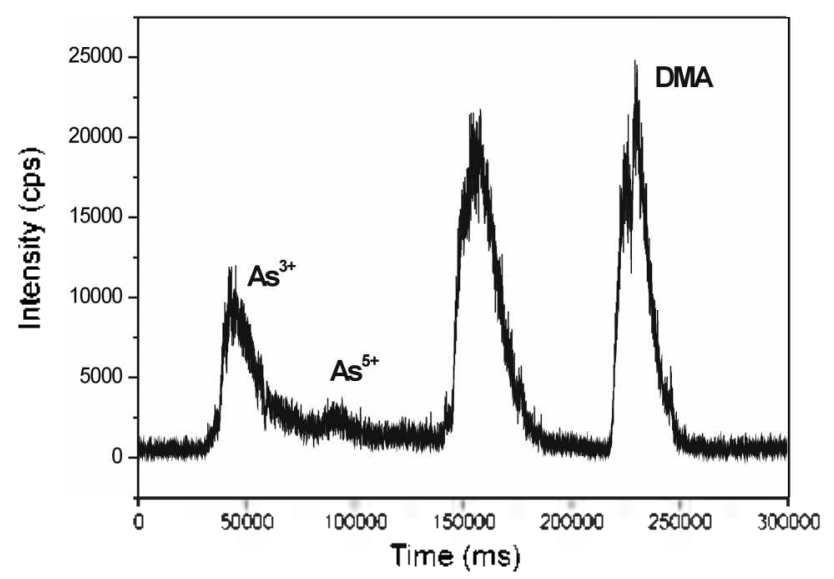

Figure 7. Chromatogram of arsenic species in a human urine. 
each five urines were also obtained from people at the age of 10 to 20.20 to 30.30 to 40 , and 40 to 50 , respectively. The concentrations of total arsenic in the urines were determined. The average concentrations of total arsenic of people at the age of 10 to 20,20 to 30.30 to 40 , and 40 to 50. were $156.62 \pm 0.51,158.87 \pm 0.07,209.93 \pm 0.62$ and $225.62 \pm 1.54 \mathrm{ng} / \mathrm{mL}$. respectively. The results are summarized in Figure 6. The results indicated the amount of total arsenic in urine was clearly increased as the age of people increased. It might be due to the accumulation of arsenic in the body after intake through various passageways such as food chains.

At last the arsenic species in an urine were determined with IC-ICP-MS. The results are shown in Figure 7. The chromatographic peaks for As(III) and DMA were clearly shown up. and a tiny peak of $A s(V)$ were also shown up. An unknown peak was also shown up. It was identified the peak was for $\mathrm{ArCl}^{-}$. The results that $\mathrm{ArCl}^{-}$does not interfere with the deternination of As species with IC-ICP-MS. The concentrations of As(III) and DMA could be determined and 3.7 and $47.3 \mathrm{ng} / \mathrm{mL}$. respectively.

\section{Conclusion}

The aim of this research was to develop the analytical method for the direct determination of arsenic species (As(III), As(V). DMA) in samples including complex matrix. The separation of As(III). As(V). DMA was successfully achieved by an AS 7 column with an isocratic elution system. The separated species were directly detected by ICP-MS. The detection limits of As(III). As(V) and DMA were 0.31, 0.45. and $2.09 \mathrm{ng} / \mathrm{mLL}$, respectively. First of all. the techuique was applied for the determination of arsenic species in a NIST SRM 1643d water sample. an As(III) was only found and determined in the sample. The measured value agreed well with the certified value. The technique was also applied for the determination of arsenic species in an urine. and the three arsenic species were identified and determined. The determination of arsenic in human urines that obtained from volunteers was also carried out. The results showed that the amount of total arsenic in human urine was increased with age

\section{References}

1. Infante. H. G.: Campenhout. K. V: Blust. R.: Adams. F. C. $J$. Anal. At. Spectrom 2002. 17. 79.

2. MeSheehy, S.; Pannier, F.: Szpunar, J : Gautier. M. P.: Lobinski. R J. Anal Af. Spectron. 2002. 127.223.

3. Moreno. P.: Quijano. M. A.: Gutierrez, A. M.; Perez-Conde, M C.: Cámara. C. J. Anal At Spectrom 2001. 16. 1044.

4. Suòr. M. A.: Devesa. V: Muòoz. O.: Vélez. D.: Montoro. R. $J$. Anal At Spectrom 2001. 16.390.

5. Heitkemper, D. T:; Vela. N. P.: Stewart, K. R.: Westphal, C. S. J. Anal At. Spectront 2001. 16, 299.

6. Marchante-Gayon, J. M.; Feldmann, I.; Thomas, C.: Jakubowski. N. J. Anal. At Spectron. 2001. 16. 457.

7. Sheppard. B. S.: Canuso. I. A.: Heithemper. D. T.: Wolnik. K. A. Analust 1992. 117.971.

8. Heitkemper, D. T.; Vela. N. P.: Stewart, K. R.: Westphal, C. S. J. Anal. Al. Spectront 2001. 16, 299.

9. Le. X. C $;$ Li, X.-F.: Lai. V.: Ma, M.: Yalcin. S.: Feldmann, J. Spectrochim. Acta. Part B 1998. 53. 899.

10. Ipoiyi. I.: Fodor. P. Anal. Chim Acta 2000. H3. 13.

11. Martinez. A.: Morales-Rubio. A.: Cervera. M. L.: Guardia. de la M. J.Anal. Af. Spectron. 2001. 16,762.

12. Muooz. O:- Vélez. D.: Montoro, R.: Arroyo, A.: Zamorano. M. J. Anal. At Spectron 2000. 15,711.

13. Ali. I.: Aboul-Eneit1. H. Y. Chemosphew 2002. 48. 275.

14. Tukai. R.: Maher. W. A.: McNaught. I. J.: Ellwood. M. J. Anal. Chim Acta 2002. 457. 173.

15. Gallardo, M. V.: Bohari. Y.: Astrue. A.: Potin-Gautier. M: Astruc. M. Anal. Chim Acta 2001, H1. 257.

16. MoSheehy, S.; Pohl, P.: Lobiñski. R.: Szpunar. J. Anal Chint Acta 2001. 40.3 .

17. Francesconi. K.: Visoottiviseth. P.: Sridokchan. W: Goessler. W. Sci. Total Eniron. 2002. 284. 27.

18. Polesello, S.: Valsecchi, S.: Cavalli. S.: Reschiotto. C. $J$ Chrontatogr. 2001. 920.231.

19. Martinez-Bravo, Y:- Roig-Navarto, A. F.: Lopez, F. J:- Hemández, F. . Chromatogr 2001. 926. 265.

20. Larsen. E. H.: Pritzl. G.: Hansen. S. H. J. Anal At. Spectrom 1993. 8. 557.

21. Wrobel. K.: Wrobel. K.: Parker, B.; Kannamkumarath. S. S.: Caruso. J. A. Taloma 2002, 58.899.

22. Anawar, H. M.; Aki, J:- Mostofa, K. M. G.: Safiullah. S.: Tarę, S M. Environnent hternational 2002. 27.597.

23. Gray. A. L. Analyst 1975. 100. 289.

24. Houk. R. S.: Fassel. V. A.: Flesch. G. D.: Svec. H. T.: Gray. A. L.: Taylor C. E. Anal Chent. 1980. 52.2283.

25. Jarvis, K. E: Gray: A. L.: Houk. R. S. Handbook of Inductinety Coupled Plasna Mass Spectronetry, Chapman and Hall: New York. 1992 